\title{
Neonatal Marfan Syndrome: Improving the Bad Prognosis with a Strict Conservative Treatment with Carvedilol?
}

\author{
Reiner Buchhorn', Tuende Kertess-Szlaninka1, Sonja Dippacher ${ }^{1}$, Martin Hulpke-Wette ${ }^{2}$ \\ ${ }^{1}$ Klinik für Kinder-Und Jugendmedizin, Caritas Krankenhaus Bad Mergentheim, Germany \\ ${ }^{2}$ Pediatric Practice, Göttingen, Germany \\ Email: reiner.buchhorn@ckbm.de
}

Received 1 May 2014; revised 1 June 2014; accepted 7 June 2014

Copyright (C) 2014 by authors and Scientific Research Publishing Inc.

This work is licensed under the Creative Commons Attribution International License (CC BY). http://creativecommons.org/licenses/by/4.0/

c) (i) Open Access

\begin{abstract}
We report about a successful heart failure therapy with carvedilol in two children with neonatal Marfan syndrome (nMFS). As shown in Case 1, double valve replacement in an infant with neonatal Marfan syndrome is feasible but its benefit on long term is uncertain. Excluding our patient, 3 infants with nMFS from the literature died early after cardiac surgery. Our second case is a unique patient who survives nMFS despite diaphragmatic herniae, dilated neonatal cisterna magna and severe atrioventricular valve insufficiencies. Treated with $0.7 \mathrm{mg} / \mathrm{kg} /$ day Carvedilol since his seventh month of life, he never developed severe heart failure. However despite his good health status at the age of 9 years, a progressive aortic root dilatation and left conornary aneurysm are still waiting for surgical repair.
\end{abstract}

\section{Keywords}

Marfan Syndrome, Neonatal Marfan Syndrom, Heart Failure, Beta Blocker, Carvedilol, Valve Surgery

\section{Introduction}

Marfan syndrome (MFS) is a rare generalized connective tissue disease with an estimated prevalence of 7 to 17 per 100,000. It is associated with mutations of the Fibrillin 1 gene located on chromosome 15q21. Neonatal MFS (nMFS) is regarded as an independent entity with most mutations in the region of exon 24 - 32 [1]. Mutations located in exon 1 to 18 are associated with classical MFS. Mutations in the exon region 18 - 24, like our Case 2, are not described in the literature yet. nMFS is associated with a poorer prognosis than adult MFS [2]. Of 60 in- 
dividuals with nMFS from the universal Marfan-data base-FBN1 (UMD-FBN1: http://www.umd.be) published in 2011, 38 had died, 82\% died before the age of 1 year. The cause of death in 88\% was heart failure. nMFS is characterized by severe cardiac manifestation with early aortic root dilatation, atrioventricular valve prolapse and severe valve regurgitation resulting in intractable heart failure. Whether medical or surgical treatment of nMFS may improve prognosis is unclear.

We report on 2 infants with neonatal MFS exhibiting heart failure as infants already due to severe atrioventricular valve prolapse and severe valve regurgitation. Based upon our investigations about beta blockers in infants's heart failure [3] [4] the children were treated with a complete $\alpha$ - and $\beta$-adrenoceptor blockade with carvedilol. At the age of 7 months, the first infant received mitral- and tricuspid valve replacement because of increasing congestive heart failure. Three months later, despite good operative result, the patient died at home with signs of rapid progressive left ventricular failure without evidence of valve dysfunction or persistent tachycardiac dysrhythmia. The second patient was treated with $0.7 \mathrm{mg} / \mathrm{kg} /$ day Carvedilol since his seventh month of life and never developed severe heart failure. The patient survives more than nine years today with a very good quality of life without any surgical treatment.

\section{Case Reports}

\subsection{Case 1}

A female infant was born at 40 weeks gestational age to a 34-year-old first gravida by spontaneous vaginal delivery. Family history for MFS was negative. The birth weight was $3380 \mathrm{~g}$ and the length $53 \mathrm{~cm}$. Apgar scores were 9 after one minute and 10 after 5 minutes. Arachnodactyly, hyperflexible joints with contractures, highly arched palate, dolichocephaly, enophthalmus, retrognathia, loose skin and low set dysplastic ears were present. Echocardiography at the first month of life showed dilatation of the ascending aorta, prolapse of both atrioventricular valves, grade II insufficiency of the mitral valve, grade III insufficiency of the tricuspid valve, grade I insufficiency of the aortic and pulmonary valve. The aortic root was enlarged, diameter of the sinus of valsalva measuring 16 mm (z-value: +2). The pulmonary root diameters were normal. Left ventricular enddiastolic diameter was enlarged measuring $26 \mathrm{~mm}$ and fractional shortening slightly decreased by $27 \%$.

The girl was treated for congestive heart failure with Carvedilol (slowly increasing doses up to a final dosage of $0.7 \mathrm{mg} / \mathrm{kg} / \mathrm{day}$ ). She started to thrive and gained $2 \mathrm{~kg}$ of weight within three months.

Clinical symptoms of congestive heart failure were discrete only. At the age of 5 month symptoms of congestive heart failure increased due to progression of mitral and tricuspid insufficiency and significant cardiomegaly developed. Additional medication with digoxin and diuretics could not improve her clinical situation on long term. Thus mitral (SJM $27 \mathrm{~mm}$ ) and tricuspid valve replacement (Carpentier-Edwards SAV bioprothesis $31 \mathrm{~mm}$ ) was performed at the age of 7 months and a bodyweight of $6.2 \mathrm{~kg}$. The patient recovered quickly after surgery and cardiomegaly was reduced significantly. After surgery supraventricular tachycardia occurred and was successfully treated with Sotalol. The patient was discharged with Digoxin, Captopril, Spironolactone and Sotalol medication. Heart failure had improved, valve function was normal and the patient continued to thrive. However three month later she died at home with signs of rapid progressive left ventricular failure without evidence of valve dysfunction or persistent tachycardia.

\subsection{Case 2}

A male infant was born at 39 weeks gestational age to a 31-year-old fourth gravida, second para, by cesarean section. Family history for MFS was negative. However the mother had two abortions and one brother died at his first day of life due to a dystrophic disorder with lung hypoplasia. The birth weight of our patient was $3180 \mathrm{~g}$, the length $51 \mathrm{~cm}$. Apgar scores were 9 after one minute and 10 after 5 minutes. A dysmorphic disorder was not primarily recognized as neonatale marfan syndrome despite facial stigmata, highly arched palate, dolichocephaly, enophthalmus, retrognathia, loose skin and low set dysplastic ears. Cranial MR imaging had shown a dilated neonatal cisterna magna [5]. Echocardiography was performed because of a heart murmur and dyspnea at the age of 7 month: it showed dilatation of the ascending aorta, prolapse of both atrioventricular valves, grade IV insufficiency of the mitral valve and grade III insufficiency of the tricuspid valve. The aortic root was enlarged, diameter of the sinus of valsalva measuring $22 \mathrm{~mm}$ (z-value: +2), Figure 1. The pulmonary root diameters were normal. Left ventricular enddiastolic diameter was enlarged measuring $39 \mathrm{~mm}$ and fractional shortening was 


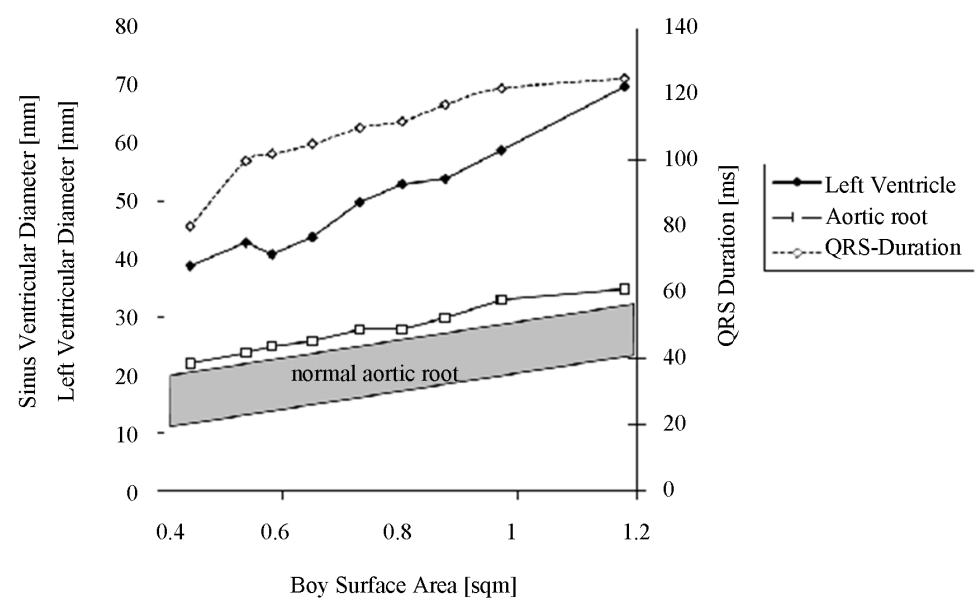

Figure 1. Echocardiographic aortic root dimensions compared to normal children [10], left ventricular diameter and prolongation of QRS Duration in a standard ECG in a boy with neonatal marfan syndrom form seventh month up to 9 years related to body surface area.

normal. He suffers from heart failure Ross Score 4, no failure to thrive and elevated NT-Pro-BNP levels up to $1149 \mathrm{pg} / \mathrm{ml}$. nMFS was diagnosed and the boy was treated with Carvedilol (slowly increasing doses up to a final dosage of $0.7 \mathrm{mg} / \mathrm{kg} /$ day). Later thoracic X-ray showed right side diaphragmatic herniae with hepatic tamponade. Intracapsular lens extraction was performed.

A fibrillin-1 mutation was found: heterozygote deletion exons 19 - 21 (ex19ex21del, FBN1). Today his height is $5 \mathrm{~cm}$ above the 97th percentile, his early macrocephaly is now in normal range and despite severe atrioventricular valve insufficiencies he never developed severe heart failure. He currently goes to school and performs low intensity sports. However the aortic root and his left ventricle was progressively dilated (Figure 1). Since his seventh year of life the main left coronary artery dilated up to $6 \mathrm{~mm}$ today.

\section{Discussion}

Both children had typical clinical signs of nMFS with predictors for a bad prognosis. Obviously, the new mutation of the Fibrillin 1 gene in the exon region 18 - 24 in Case 2 causes nMFS. It remains unclear if the early death of his brother is also caused by this mutation and whether the bad prognosis of this mutation is the cause. For the first time, we report about a successful heart failure therapy with carvedilol in nMFS. As shown in Case 1, double valve replacement in an infant with neonatal Marfan syndrome is feasible but its benefit on long term is uncertain. Excluding our patient, 3 infants with nMFS from the literature died early after cardiac surgery [6]. One case report showed a good late follow-up 9 years after Bentall-De Bonon procedure at 2 years of age [7]. However, this patient had no atrioventricular valve regurgitation. If the typical fibrillin 1 gene mutation was not reported, this case seems to be an early diagnosed classical MFS. All 6 patients with diaphragmatic hernia and nMFS died in the first months of life (range 0 - 3.5 months) [8]. Our second case is a unique patient who survives nMFS despite diaphragmatic herniae, dilated neonatal cisterna magna and severe atrioventricular valve insufficiencies. Treated with $0.7 \mathrm{mg} / \mathrm{kg} /$ day Carvedilol since his seventh month of life he never developed severe heart failure. However despite his good health status at the age of 9 years, a progressive aortic root dilatation and left conornary aneurysm [9] are still waiting for surgical repair. Perhaps this unique clinical course depends on the unique fibrillin-1 mutation, which has never been published before. However together with his parents we decided for a strict conservative treatment based on carvedilol to prevent heart failure, cardiovascular shear stress and perioperative sympathetic activation. Based on this extraordinary strategy he is the fifth oldest nMFS patient from the universal Marfan-data base-FBN1 published in 2011 and the only survivor with this unique high risk profile.

\section{References}

[1] Kirschner, R., Hubmacher, D., Iyengar, G., Kaur, J., Fagotto-Kaufmann, C., Bromme, D., Bartels, R. and Reinhardt, 
D.P. (2011) Classical and Neonatal Marfan Syndrome Mutations in Fibrillin-1 Cause Differential Protease Susceptibilities and Protein Function. Journal of Biological Chemistry, 286, 32810-32823.

http://dx.doi.org/10.1074/jbc.M111.221804

[2] Stheneur, C., Faivre, L., Collod-Beroud, G., Gautier, E., Binquet, C., Bonithon-Kopp, C., Claustres, M., Child, A.H., Arbustini, E., Ades, L.C., Francke, U., Mayer, K., Arslan-Kirchner, M., De Paepe, A., Chevallier, B., Bonnet, D., Jondeau, G. and Boileau, C. (2011) Prognosis Factors in Probands with an FBN1 Mutation Diagnosed before the Age of 1 Year. Pediatric Research, 69, 265-270. http://dx.doi.org/10.1203/PDR.0b013e3182097219

[3] Buchhorn, R., Hulpke-Wette, M., Hilgers, R., Bartmus, D., Wessel, A. and Bursch, J. (2001) Propranolol Treatment of Congestive Heart Failure in Infants with Congenital Heart Disease: The CHF-PRO-INFANT Trial. Congestive Heart Failure in Infants Treated with Propanol. International Journal of Cardiology, 79, 167-173. http://dx.doi.org/10.1016/S0167-5273(01)00413-2

[4] Buchhorn, R., Hulpke-Wette, M., Ruschewski, W., Ross, R.D., Fielitz, J., Pregla, R., Hetzer, R. and Regitz-Zagrosek, V. (2003) Effects of Therapeutic Beta Blockade on Myocardial Function and Cardiac Remodelling in Congenital Cardiac Disease. Cardiology in Young, 13, 36-43. http://dx.doi.org/10.1017/S1047951103000076

[5] Vasu, V., Child, A.H., Modi, N., Rutherford, M. and Cowan, F. (2011) Dilated Neonatal Cisterna Magna and Marfan Syndrome. BMJ Case Report.

[6] Stheneur, C., Faivre, L., Collod-Beroud, G., Gautier, E., Binquet, C., Bonithon-Kopp, C., Claustres, M., Child, A.H., Arbustini, E., Ades, L.C., Francke, U., Mayer, K., Arslan-Kirchner, M., De Paepe, A., Chevallier, B., Bonnet, D., Jondeau, G. and Boileau, C. (2011) Prognosis Factors in Probands with an FBN1 Mutation Diagnosed before the Age of 1 Year. Pediatric Research, 69, 265-270. http://dx.doi.org/10.1203/PDR.0b013e3182097219

[7] Brito-Filho, S.L., Oporto, V., Campos, O., Alvares, A.B. and Carvalho, A.C. (2013) A Case of Neonatal Marfan Syndrome with Good Late Follow-Up: Is It Possible to Avoid an Early Unfavourable Outcome? Cardiology in Young, 23, 301-303. http://dx.doi.org/10.1017/S104795111200090X

[8] Stheneur, C., Faivre, L., Collod-Beroud, G., Gautier, E., Binquet, C., Bonithon-Kopp, C., Claustres, M., Child, A.H., Arbustini, E., Ades, L.C., Francke, U., Mayer, K., Arslan-Kirchner, M., De Paepe, A., Chevallier, B., Bonnet, D., Jondeau, G. and Boileau, C. (2011) Prognosis Factors in Probands with an FBN1 Mutation Diagnosed before the Age of 1 Year. Pediatric Research, 69, 265-270. http://dx.doi.org/10.1203/PDR.0b013e3182097219

[9] Williams-Phillips, S. (2012) Marfan’s Syndrome: Pre-Pubertal Aortic Rupture with Left Coronary Artery Aneurysms and Fistulas. West Indian Medical Journal, 61, 937-940. http://dx.doi.org/10.7727/wimj.2012.233

[10] Roman, M.J., Devereux, R.B., Kramer-Fox, R. and O’Loughlin, J. (1989) Two-Dimensional Echocardiographic Aortic Root Dimensions in Normal Children and Adults. American Journal of Cardiology, 64, 507-512. http://dx.doi.org/10.1016/0002-9149(89)90430-X 